\title{
FormaÇÃo INICIAL DE PROFESSORES DE MATEMÁtiCA FRENTE Às TECNOLOGIAS DIGITAIS
}

\author{
INITIAL FORMATION OF MATHEMATICS TEACHERS IN DIGITAL TECHNOLOGIES
}

FORMACIÓN INICIAL DE PROFESORES DE MATEMÁTICAS EN TECNOLOGÍAS DIGITALES

\author{
Patrícia Zanon Peripolli \\ (iD) 9 \\ Doutoranda em Ensino de Ciência \\ e Matemática (UFN) \\ Discente do Programa de Pós- \\ Graduação em Ensino de Ciência e \\ Matemática da Universidade \\ Franciscana (PPGECIMAT/UFN) \\ patriciazperipolli@gmail.com
}

\begin{abstract}
Resumo
A sociedade contemporânea demanda uma ressignificação no processo de ensino e aprendizagem. Com isso, o ensino mediado pelas tecnologias digitais tem despertado o interesse de vários pesquisadores. Assim, este trabalho relata uma experiência desenvolvida na formação inicial de professores de matemática que teve o intuito de estimular o uso das tecnologias digitais. A pesquisa foi realizada na disciplina de Prática enquanto Componente Curricular, com dez acadêmicos da licenciatura em matemática de uma instituição pública. Foi escolhido como ambiente de mediação virtual o Facebook. Ademais, trabalhouse com a construção de mapas conceituais, com histórias em quadrinhos e com o software GeoGebra para a elaboração de atividades de ensino. Os resultados evidenciaram que o uso de recursos tecnológicos na formação inicial de professores de matemática contribui para o desenvolvimento de atividades de ensino, as quais integram conceitos matemáticos com recursos tecnológicos, de modo a despertar a criatividade, estimular o interesse dos estudantes e desenvolver o conhecimento matemático.

Palavras-chave: Ensino de matemática. Formação de professores. Mapas conceituais. Histórias em quadrinhos. GeoGebra.
\end{abstract}

Recebido em: 7 de julho de 2021 .

Aprovado em: 2 de outubro de 2021.

Como citar esse artigo (ABNT):

PERIPOLLI, Patrícia Zanon. Formação inicial de professores de matemática frente às tecnologias digitais. Revista Prática Docente, v. 6, n. 3, e084, 2021. http://doi.org/10.23926/RPD.2021.v6.n3.e084.id1259 


\section{Abstract}

Contemporary society demands a new meaning in the teaching and learning process. Thus, teaching mediated by digital technologies has aroused the interest of many researchers. Thus, this paper reports an experience developed in the initial training of mathematics teachers that aimed to encourage the use of digital technologies. The research was carried out in the discipline of Practice as a Curriculum Component, with ten academics from a degree in mathematics from a public institution. Facebook was chosen as the virtual mediation environment. Furthermore, we worked with the construction of concept maps, comic books and the GeoGebra software for the elaboration of teaching activities. The results showed that the use of technological resources in the initial training of mathematics teachers contributes to the development of teaching activities, which integrate mathematical concepts with technological resources, in order to awaken creativity, stimulate student interest and develop knowledge mathematical.

Keywords: Math teaching. Teacher training. Concept maps. Comics. GeoGebra.

\section{Resumen}

La sociedad contemporánea exige un nuevo significado en el proceso de enseñanza y aprendizaje. Así, la docencia mediada por tecnologías digitales ha despertado el interés de varios investigadores. Así, este trabajo reporta una experiencia desarrollada en la formación inicial de profesores de matemáticas que tuvo como objetivo incentivar el uso de tecnologías digitales. La investigación se llevó a cabo en la disciplina de la Práctica como Componente Curricular, con diez académicos de una licenciatura en matemáticas de una institución pública. Se eligió Facebook como entorno de mediación virtual. Además, se trabajó con la construcción de mapas conceptuales, cómics y el software GeoGebra para el desarrollo de actividades docentes. Los resultados mostraron que el uso de recursos tecnológicos en la formación inicial de profesores de matemáticas contribuye al desarrollo de actividades docentes, que integran conceptos matemáticos con recursos tecnológicos, con el fin de despertar la creatividad, estimular el interés de los estudiantes y desarrollar conocimientos matemáticos.

Palabras clave: Enseñanza de matemáticas. Formación de profesores. Mapas conceptuales. Cómics. GeoGebra. 


\section{INTRODUÇÃO}

As transformações da sociedade contemporânea requerem uma ressignificação no processo de ensino e aprendizagem, com a utilização de variados métodos de ensino, oferta de novas alternativas para os sujeitos se expressarem e interagirem. Desse modo, diversificam-se as formas de ensinar, agir e aprender, levando em conta a realidade e os diferentes contextos (MARTINSI, 2008).

Para atingir tal ressignificação, é preciso levar em conta o modo como é estruturado o currículo dos cursos de licenciatura. Isso se faz necessário, pois a formação inicial de professores deve oferecer suporte adequado e possibilitar que os acadêmicos vivenciem experiências envolvendo metodologias e estratégias que contemplem o uso das Tecnologias Digitais. Desse modo, quando começarem a atuar em sua área, terão mais condições de desenvolver práticas adequadas e que gerem interesse por parte desta nova geração de alunos.

Neste sentido, os cursos de licenciatura passaram a incluir em seus currículos Práticas enquanto Componente Curricular (PeCC), que possibilitam o desenvolvimento pedagógico para os mais diversos contextos. A PeCC passou a fazer parte do Projeto Pedagógico do Curso Superior de Licenciatura em Matemática mediante resolução do CONSUP nº 161/2014, de 28 de novembro de 2014, sendo ofertada a cada semestre do curso (BRASIL, 2014).

A disciplina PeCC dá ênfase para a reflexão e observação, proporcionando a atuação investigativa e a contextualização da prática educativa em diferentes situações. Essa disciplina pode ser aprimorada com envolvimento de outras, associando conhecimentos específicos já estudados, em uma perspectiva interdisciplinar. Assim é possível integrar a formação à prática docente (BRASIL, 2014).

A PeCC é uma disciplina que possibilita o desenvolvimento de atividades envolvendo o uso de diferenciadas metodologias, propicia conhecer e utilizar recursos tecnológicos e produzir materiais didáticos que oferecem subsídios teóricos e práticos. Além disso, estimula o acadêmico a vivenciar situações que posteriormente possam ser implementadas em seus planejamentos e ações docentes.

Nesse viés, a temática articuladora da PeCC IV é a formação do professor de matemática na perspectiva de práticas inovadoras envolvendo diferentes recursos tecnológicos. Este trabalho tem o objetivo de apresentar a prática desenvolvida com os licenciandos, de modo que estimule o uso das tecnologias digitais no processo de ensino e aprendizagem da matemática. 
Dessa forma, será contemplada, neste artigo, uma discussão sobre a importância da inserção das tecnologias na formação inicial de professores de matemática, além de apontamentos referentes a alguns recursos tecnológicos apresentados e utilizados pelos acadêmicos. Em seguida, será apresentada a metodologia empregada neste estudo, na sequência, os resultados e discussões e, por fim, as considerações finais.

\section{IMPORTÂNCIA do USo dAS TECNOLOgIAS Digitais NA FoRMAÇão INICIAL DE Professores de MATEMática}

Ao trabalhar com a formação inicial de professores, é preciso considerar que esses serão os profissionais que vão atuar com alunos que estão incorporados no entorno digital, que chegam na escola e desejam encontrar algo que os desafie e os faça ampliar seus conhecimentos e habilidades. Em vista disso, verifica-se a importância de formar futuros profissionais qualificados para trabalhar com as tecnologias digitais, de modo a utilizá-las de forma significativa em sua prática.

Acredita-se que, se as tecnologias forem inseridas nas práticas de ensino no decorrer da formação inicial, e se os licenciandos forem incentivados a desenvolver atividades envolvendoas, isso possibilitará que esses assumam novos posicionamentos frente às tecnologias e o seu papel para a educação. Esse profissional será capaz de identificar as suas características, fragilidades e potencialidades e, a partir disso, desenvolver competências e habilidades para abordar conteúdos matemáticos integrados às tecnologias. Assim haverá contribuição para uma apropriação crítica e consciente destas em suas ações futuras na docência (GONÇALVES; MARCO, 2020; LOPES, 2010).

Conforme Kenski (2013) e Passerino (2010) discorrem, a formação inicial de professores precisa atender às exigências da sociedade provenientes dos avanços tecnológicos, com a realização de atividades em que os licenciandos possam conhecer, explorar, desenvolver conhecimentos e se sentir motivados a utilizar as tecnologias digitais em diferentes contextos e realidades.

Dessa forma, nos cursos de formação inicial de professores de matemática, não pode ser feito um treinamento de técnicas e métodos para utilizar as tecnologias digitais, mas sim proporcionar aos licenciandos um espaço para conhecerem e refletirem sobre a prática que pretendem adotar futuramente, além de analisar convicções teóricas e repensar o ensino e aprendizagem de matemática. 
Assim, mobiliza-se nos licenciandos uma prática crítica e reflexiva, de modo a gerar autonomia de pensamento, a qual incidirá nas decisões sobre a própria formação. Além disso, o docente contará com meios para a construção da sua identidade pessoal, profissional e institucional, fornecendo condições para superar possíveis dificuldades encontradas no início da carreira, as quais podem resultar na "acomodação às formas vigentes de ensino" (FÜRKOTTER; MORELATTI, 2008, p. 56).

Observa-se que a sociedade vem exigindo um ensino de matemática que prepare as novas gerações para lidar com ambientes virtuais, com recursos tecnológicos, para que consigam interpretar as inúmeras informações disponíveis na rede, de modo a formar estudantes com capacidade de pensar de forma flexível, crítica e criativa (MARCO, 2009).

Diante disso, Miskulin e Viol (2014, p. 1313) ressaltam que os professores e licenciandos precisam estar preparados para encarar as novas possibilidades de organizar, planejar e ministrar as aulas com criatividade, adotando diferentes posturas em relação ao uso de recursos tecnológicos disponíveis, desenvolver "novas maneiras de gerar e dominar o conhecimento, novas formas de produção e apropriação do conhecimento na prática docente $[\ldots] "$.

Acredita-se que as tecnologias digitais devem estar disponíveis aos licenciandos, de modo que as conheçam como recursos didáticos pedagógicos para incentivar o desenvolvimento de estratégias de ensino, e de forma a se sentirem seguros para inseri-las criticamente em sua prática docente.

A formação inicial deve preparar os futuros professores para que sejam capazes de se apropriarem das tecnologias digitais e, a partir disso, passarem a desenvolver seus próprios materiais didáticos ou adaptar os que estão disponíveis na web, de forma que possam servir como recurso pedagógico para suas aulas de matemática.

Almeida, Rezende e Lima (2013) colaboram com essa percepção e destacam que o professor, ao utilizar esses conhecimentos para o desenvolvimento de sua prática pedagógica, retira-se da condição de mero consumidor das tecnologias e insere-se na condição de protagonista, que explora e interpreta sua própria realidade, o que possibilita a construção de seus próprios materiais de acordo com sua necessidade e adequados ao contexto local.

As diretrizes Curriculares Nacionais para a Formação Inicial de Professores para a Educação Básica evidenciam a importância dos licenciandos estarem aptos a relacionar os meios de comunicação com a educação, de forma didática e pedagógica, demonstrando domínio 
dos recursos tecnológicos para o desenvolvimento da aprendizagem (BRASIL, 2019). Dentre as competências gerais, é recomendado que o docente realize:

[...] a curadoria educacional, utilizar as tecnologias digitais, os conteúdos virtuais e outros recursos tecnológicos e incorporá-los à prática pedagógica, para potencializar e transformar as experiências de aprendizagem dos estudantes e estimular uma atitude investigativa (BRASIL, 2019, p. 13).

Nessa perspectiva, fica clara a necessidade de proporcionar ações formativas, nos cursos de formação inicial de professores, para a utilização de tecnologias digitais. Mais do que isso, uma formação que possibilite ao acadêmico utilizar as tecnologias para fazer educação, conhecer e usá-las para a organização de ambientes interativos e dinâmicos de ensino e aprendizagem.

Assim, observa-se que a disciplina da PeCC, ofertada nos cursos de Licenciatura em Matemática, a cada semestre, constitui "um espaço de criação e reflexão acerca do trabalho do docente e do contexto social em que se inserem, com vistas à integração entre a formação e o exercício do trabalho docente" (BRASIL, 2014).

Nessa perspectiva, a disciplina prática proporciona aos licenciandos relacionar os conhecimentos específicos aprendidos no curso, conhecer e estudar as tecnologias, as diversas abordagens metodológicas. Além disso, os acadêmicos, ao se apropriarem desses conhecimentos no decorrer da formação, têm mais chances de sucesso ao desenvolverem atividades que integrem estas temáticas, de acordo com a realidade de cada contexto escolar.

A PeCC IV, a qual buscamos detalhar neste artigo, tem o objetivo de apresentar recursos tecnológicos que podem ser implementados nas aulas de matemática, de modo a contribuir para o desenvolvimento do ensino e aprendizagem. Além disso, possibilita investigar o contexto escolar e, assim, incentivar os licenciandos a conhecerem, apropriarem-se das especificidades dos recursos tecnológicos e, com isso, desenvolverem atividades que os envolvem. Tais atividades visam a auxiliar na compreensão de conceitos matemáticos, a tornar as aulas mais dinâmicas e a otimizar o desenvolvimento do ensino de matemática.

Dessa forma, optou-se em apresentar alguns recursos tecnológicos como: o Facebook, como elemento de ampliação da sala de aula e repositório das atividades produzidas na disciplina; o CmapTools, ferramenta para a construção de mapas conceituais; o Toondoo e o Pixton, para a construção de histórias em quadrinhos; o GeoGebra, software matemático que permite melhor visualização de figuras de diferentes modos, realizar movimentos, recursos esses que podem auxiliar no processo de ensino e aprendizagem. 


\subsection{FACEBOOK}

Atualmente as redes sociais têm se tornado onipresentes no cotidiano dos estudantes, na maioria dos níveis de ensino. Assim, alguns educadores iniciaram discussões e estudos em relação às potencialidades e desafios da utilização das redes sociais no contexto educativo. Dentre as redes mais utilizadas no Brasil, está o Facebook (CHEN; BRYER, 2012; ELLENSOHN; BARIN, 2016; TUCUNDUVA, 2021).

O Facebook dispõe de ferramentas de comunicação, síncronas e assíncronas, que o tornam um espaço de interação, experiências e aprendizagem colaborativa em rede, por meio do diálogo e da construção coletiva de conhecimentos entre os envolvidos (SCHERER; FARIAS, 2018).

Nessa perspectiva, acredita-se que o uso do Facebook como elemento de ampliação da sala de aula favorece a troca de informações entre professores e estudantes, pois percebe-se que os alunos, ao se sentirem mais à vontade para se expressar, trocam informações de modo fluido e natural, o que oportuniza a construção de saberes na coletividade. Segundo Moran (2012), o uso das redes sociais possibilita aos professores e estudantes uma alteração na dinâmica das aulas, tornando um momento de incentivo a participação e envolvimento dos estudantes no processo de ensino e aprendizagem.

\subsection{Mapas CONCEITUAis}

Os mapas conceituais têm se destacado no campo educacional, pois se apresentam como recursos facilitadores da aprendizagem, uma vez que se fundamentam na Teoria da Aprendizagem Significativa de David Ausubel. O mapa conceitual é um instrumento para organizar e representar a construção do conhecimento (NOVAK; CAÑAS, 2010).

A estrutura básica dos mapas conceituais é uma representação gráfica do conhecimento, constituída por relações entre conceitos e exemplos organizados hierarquicamente e relacionados por conectores que formam proposições (MOREIRA, 2012). O mapa conceitual se torna uma ferramenta pedagógica ainda mais atrativa quando são utilizados recursos das tecnologias digitais para construí-lo e enriquecê-lo, ampliando o potencial criativo (MOUSINHO, 2020).

A inserção dos mapas conceituais nas aulas possibilita ao aluno: relacionar conhecimentos prévios com os obtidos após leituras, pesquisas e discussões; realizar a interpretação de textos; organizar e identificar as ideias principais, contribuindo para o desenvolvimento do conhecimento. Para o professor, o mapa conceitual é uma ferramenta que 
permite identificar o conhecimento que o aluno possui; verificar o progresso do aluno em relação à temática estudada, sendo utilizado como instrumento avaliativo que possibilita realizar o acompanhamento e a verificação da aprendizagem. Diante disso, entende-se que, ao utilizar os mapas conceituais nas aulas, estes proporcionam melhor compreensão dos conceitos estudados, estimula a consciência crítica e aguça o desejo do aluno pelo aprendizado.

\subsection{HiSTÓRIAS EM QUADRINHOS}

As Histórias em Quadrinhos (HQ) informa, diverte e comunica seu público há mais de um século. Sua linguagem atraente e simples instiga a atenção dos alunos pelo assunto. As HQ são ferramentas que podem auxiliar no processo de ensino e aprendizagem, visto que tornam o conteúdo mais atrativo e envolvente, através de imagens, falas e contexto da história.

As Histórias em Quadrinhos têm sido adotadas como recurso didático pelos professores de matemática a fim de abordar uma diversidade de conteúdo, possibilitando trabalhar com a integração entre diferentes áreas de estudo, estimular a reflexão, a criticidade, e a criatividade. Segundo Cordeiro, Cardozo e Silva (2018), embora seja crescente a utilização de HQ no ensino, ainda é pequeno o número de professores que têm usado esse recurso para auxiliar na prática docente.

Vale destacar ainda que as HQ possibilitam potencializar o ensino e aprendizagem de matemática, especialmente quando associadas a resolução de problema, pois diante das situações-problema apresentadas nos desenhos, o estudante consegue expor sua crítica, interpretar a mensagem passada, mostrar seus conhecimentos prévios, desenvolver o pensamento lógico, além de permitir contextualizar conceitos em situações cotidianas e, com isso, interpretar com facilidade a linguagem matemática (PERIPOLLI; BARIN, 2018).

Atualmente existe uma variedade de recursos tecnológicos que permitem a criação de HQ, de forma prática e intuitiva, como por exemplo: o Toondoo, o Pixton, entre outros, que permitem a criação de histórias em quadrinhos de forma online, disponibilizam uma variedade de cenários, personagens, objetos, balões de diálogo, a fim de produzir histórias em quadrinhos personalizada, de forma rápida e fácil, facilitando assim, sua inserção no ambiente educacional. O professor pode usá-las para trabalhar diferentes conteúdos, assim como propor atividade em que os alunos utilizem sua imaginação e conhecimentos para criarem as suas próprias HQ.

\subsection{GEOGEBRA}


O GeoGebra é um software criado para a construção de conceitos e objetos matemáticos. É uma ferramenta de estudo, que contempla tópicos de matemática como: geometria, álgebra e cálculo. Pode ser utilizado no ensino fundamental, médio e superior. Apresenta relevantes contribuições para o ensino de matemática em virtude da sua dinâmica de funcionalidades, acessibilidade e facilidade para uso, tornando-se, assim, um recurso que permite utilizar abordagens diferenciadas para estudar diversos conceitos matemáticos em apenas uma interface gráfica (SOUSA; AZEVEDO; ALVES, 2021).

De modo geral, a principal potencialidade do GeoGebra é o modo como permite manipular, movimentar os gráficos e figuras geométricas de forma contínua e em tempo real, sem alterar as propriedades da construção inicial. Esse aspecto torna as aulas mais dinâmicas, pois permite que o aluno visualize a matemática em movimento enquanto o professor explica (MOURA; SANTOS; SILVA, 2016).

O GeoGebra fornece uma dimensão que supera o plano de visão imaginário proposto nas aulas tradicionais, envolvendo papel, régua, lápis, quadro e giz. Além disso, possibilita, a partir de suas funcionalidades, que o aluno aprenda de forma interativa, através do movimento, da experimentação e visualização dos conceitos matemáticos potencializando o desenvolvimento do conhecimento.

Acredita-se que as tecnologias têm grande potencial para auxiliar no processo de ensino de matemática, mas, para isso, estas precisam ser utilizadas de modo dinâmico, inovador, associadas a abordagens diferenciadas, de modo a tornar as aulas um ambiente interativo para o desenvolvimento da aprendizagem matemática. Vale salientar, no entanto, que não é o fato de utilizar tecnologias no processo de ensino que fará com que o aluno aprenda, e sim como utilizamos estes recursos e como promovemos a construção deste processo (MORAES; KOSLOWSKI; NONENMACHER, 2016). Além disso, Moran (2012) ressalta que o uso das tecnologias tem potencial para enriquecer o processo de ensino e aprendizagem, desde que seja empregado de forma contextualizada.

\section{Metodologia}

Este trabalho está pautado na metodologia da pesquisa-ação, com uma abordagem qualitativa, a qual implica na interação entre pesquisador e participantes da investigação, para a análise da realidade encontrada e construção do conhecimento (THIOLLENT, 2018).

A pesquisa foi realizada no segundo semestre de 2019, na disciplina de PeCC, no curso de Licenciatura em Matemática de uma Instituição Pública situada na região central do Rio 
Grande do Sul. Os participantes da pesquisa foram 10 licenciandos e a docente. A disciplina é ofertada no quarto semestre do curso e aborda conceitos matemáticos relacionados a recursos das tecnologias digitais, tendo aulas teóricas e práticas. Além do espaço formal de sala de aula, foi adotado, como ambiente de mediação virtual, o Facebook em um grupo fechado. Assim sendo, tanto a sala de aula quanto o Facebook foram fontes diretas de dados geradas no decorrer das situações de estudo, envolvendo todos os agentes da pesquisa (participante - pesquisador objeto).

No decorrer do semestre, foram planejadas, implementadas e avaliadas propostas de atividades de ensino e aprendizagem que envolvessem recursos das tecnologias digitais como mediadores do processo, tais como criação de mapas conceituais, e atividades envolvendo histórias em quadrinhos e o GeoGebra. As propostas foram disponibilizadas com diferentes objetivos: desenvolver a interpretação, o senso crítico e a investigação; despertar a curiosidade em relação aos recursos tecnológicos; potencializar a aprendizagem e avaliar os acadêmicos.

No término da disciplina, os acadêmicos responderam a um questionário online, construído no Google formulários e disponibilizado no Facebook. Este continha questões sobre suas percepções em relação à proposta da disciplina e sugestões para a sua melhoria.

\section{RESUltados E Discussões}

Os acadêmicos não estavam acostumados a utilizar uma plataforma de apoio na sala de aula para a disponibilização de conteúdos e atividades. Então, ao propor o uso da rede social Facebook, a aceitação foi ótima pela maioria dos estudantes, sendo que no início teve a resistência de dois alunos. Porém logo perceberam que este recurso facilitaria o processo e passaram a usar e interagir nas atividades propostas.

Vale destacar um dado relevante sobre as redes sociais, pois proporcionam aos estudantes se expressarem com maior liberdade no ambiente virtual do que no ambiente presencial, favorecendo assim a troca de informação entre acadêmico e acadêmico, acadêmico e docente, dado que esta troca flui naturalmente. Faria (2004) corrobora com esse pensamento ao afirmar que o docente, ao desafiar, problematizar e pesquisar juntamente com os estudantes, através dos usos das tecnologias nas quais os jovens já estão mais habituados, beneficia a interatividade.

A cada semana, eram postados no grupo do Facebook materiais, artigos que pudessem colaborar com o conhecimento teórico referente aos recursos tecnológicos que estávamos 
trabalhando presencialmente, apresentando suas potencialidades para o ensino de matemática, estratégias de aplicação, entre outros.

Assim, na primeira atividade, foram disponibilizados alguns artigos que abordavam sobre: a importância do uso das tecnologias; a necessidade de inserção dessas nas atividades escolares; as dificuldades enfrentadas para utilizar as tecnologias no processo de ensino e aprendizagem de matemática. Desse modo, a turma foi dividida em três grupos, que precisavam realizar a leitura dos artigos e fazer uma síntese destes, apresentando-a por meio de um mapa conceitual.

Esta atividade foi proposta pensando que o uso dos mapas conceituais contribuiria para que os acadêmicos realizassem correlação com diferentes conceitos e possibilitasse melhor compreensão por parte deles ao criar esquemas.

Desta forma, na aula presencial, a docente apresentou exemplos de mapa conceitual, explicou sua origem, sua fundamentação, que ele é utilizado geralmente para interpretar textos, organizar ideias, construir novos conhecimentos, além de ser muito usado para realizar avaliações, também apresentou tipos de mapas e orientou os acadêmicos como construir bons mapas e quais os principais elementos que devem compor um mapa conceitual.

Para a realização da atividade, foi disponibilizado, no Facebook, o link para baixar o software CmapTools, para a confecção dos mapas, bem como tutoriais que auxiliasse os acadêmicos no desenvolvimento desse trabalho. A opção pelos mapas conceituais pautou-se na possibilidade de verificar a organização do conhecimento de seus criadores em relação à temática em estudo.

Este tipo de atividade proporciona a produção criativa dos acadêmicos, o que pode contribuir mais efetivamente para o seu aprendizado. De acordo com Moreira (2012), os mapas conceituais, criados por Novak, têm como objetivo desenvolver a aprendizagem significativa e colaborar para a atribuição de novos significados aos conceitos de ensino, aprendizagem e avaliação.

Ao término desta atividade foi solicitado que os licenciandos compartilhassem seus mapas conceituais no grupo do Facebook. Isto permitiu que os acadêmicos observassem as diferentes formas de esquematizar e organizar os conhecimentos, possibilitando conhecer outros modos de relacionar os conceitos e auxiliar na melhora da compreensão desta temática.

Na figura 1, apresentamos alguns mapas conceituais produzidos pelos licenciandos. 
Figura 1 - Mapas conceituais produzidos pelos licenciandos
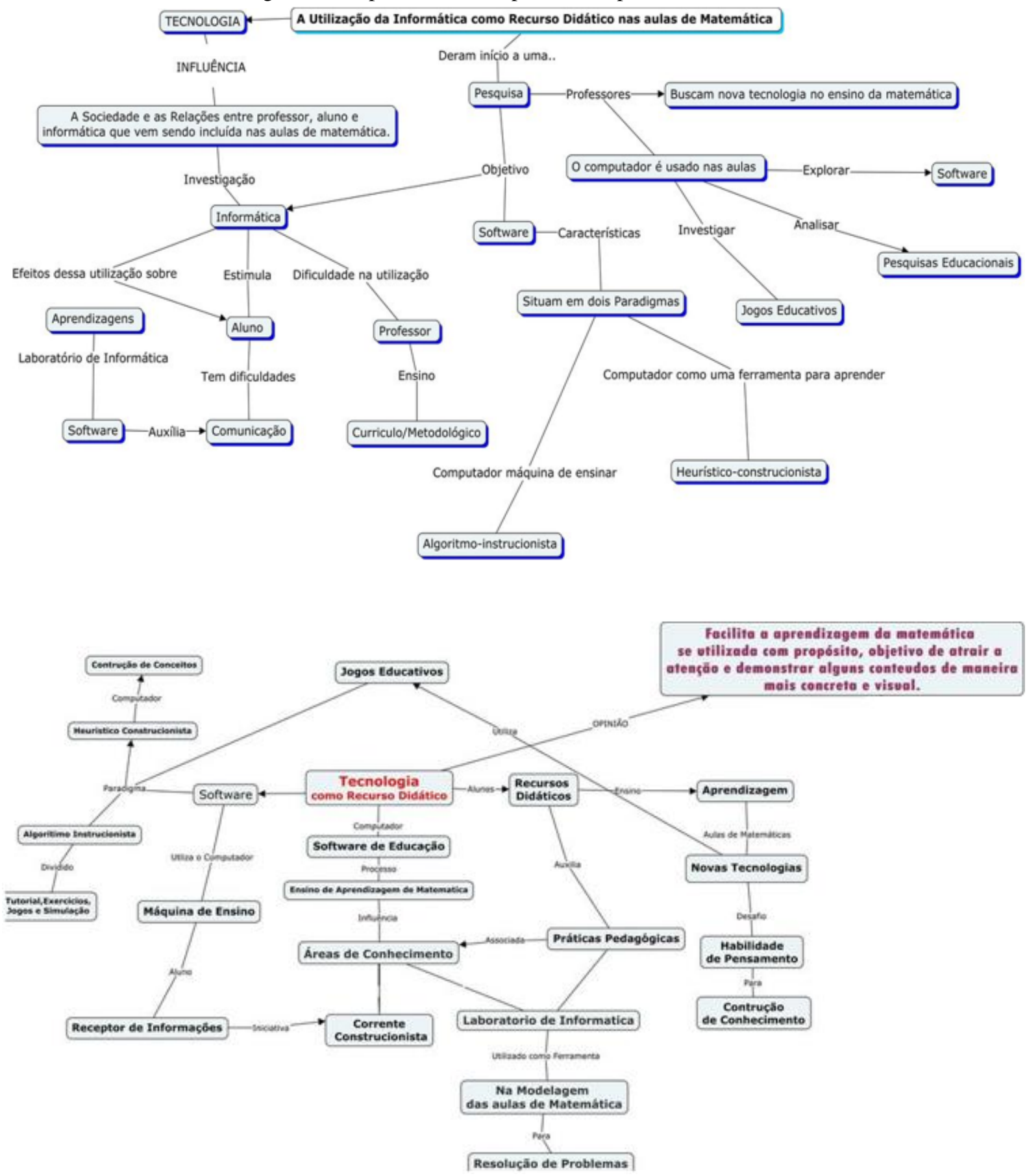

Fonte: Dados da pesquisa.

Os mapas conceituais construídos pelos licenciandos apresentaram as interrelações entre os conceitos de forma adequada, sendo os resultados obtidos decorrentes desta atividade. Ao observar a figura, percebe-se que os acadêmicos conseguiram elencar e associar a temática a vários conceitos que estão diretamente relacionados ao uso de recursos tecnológicos no ensino de matemática. 
Além disso, ao compartilhar os mapas conceituais no grupo do Facebook, os licenciandos deveriam comentar nas postagens, apontando melhorias e fragilidades no trabalho de seus pares. Com isso, percebeu-se a importância de proporcionar momentos para dialogar, discutir, trocar informações entre os pares, que de acordo com Glasser (2017) quanto mais é estimulada a interação, e o compartilhamento de conhecimento de modo ativo, maior é o índice de informações assimilado, de modo a desenvolver melhorias na aprendizagem.

Com essa tarefa, foi possível verificar que o uso de redes sociais, de forma planejada e orientada, torna-se um ambiente propício para a discussão, tornando um espaço de partilha e aprendizagem, engajando os acadêmicos para a construção e melhorias do material produzido, além de contribuir para o desenvolvimento do conhecimento.

A segunda atividade teve como objetivo apresentar as histórias em quadrinhos como estratégias potencializadoras para o ensino, pois se definem por uma linguagem diferenciada e atraente, a qual desperta atenção do acadêmico pelo assunto estudado. Porém, no ensino de matemática, elas ainda são pouco utilizadas, sendo necessário inseri-las na prática escolar.

Alguns autores relatam que, ao utilizar as histórias em quadrinhos como mediadoras do processo de ensino e aprendizagem nas aulas de matemática, estas possibilitam melhor entendimento dos conceitos, estimulam a leitura, incentivam a criatividade e auxiliam no processo de interpretação da linguagem matemática. Isso se dá devido à forma como são estruturadas, através de cenários, personagens, diálogos, gerando um melhor desempenho da memória (FRIZZO; BERNARDI, 2001, PERIPOLLI, BARIN, 2018).

Segundo Tonon (2009), as histórias em quadrinhos são excelentes instrumentos lúdicos para fazer com que os conhecimentos matemáticos se tornem significativos para os alunos, visto que incentivam os alunos a participarem ativamente das aulas, contribuem para a compreensão dos conteúdos estudados, aguçando a curiosidade e o senso crítico.

Nesse sentido, foi proposta a atividade envolvendo as histórias em quadrinhos, sendo inicialmente explicada pela docente, na aula presencial, o potencial do uso das HQ para o ensino de matemática, assim como as possibilidades de inserção no contexto da matemática: de forma a introduzir conteúdo, estimulando o estudante a refletir sobre o tema abordado; de modo explicativo no decorrer do diálogo, esclarecendo fatos, conceitos; através da inserção de problemas matemáticos, estimulando o estudantes a levantar questionamentos. Em seguida, a docente apresentou dois recursos tecnológicos, o Tondoo e o Pixton, que permitem a criação de histórias em quadrinhos personalizadas de forma online. 
Dando sequência, foi solicitado aos licenciandos criar Histórias em Quadrinhos nos sites apresentados, utilizando os variados recursos que dispõem. Integrando ao contexto da HQ com um conteúdo de matemática do Ensino Médio e relacionasse com situações cotidianas. Logo após, deviam compartilhar no grupo privado do Facebook e explicar como utilizariam a HQ em sua aula. A partir da Figura 2, podemos observar algumas produções dos licenciandos.

Figura 2 - HQ problematizando Progressão Aritmética

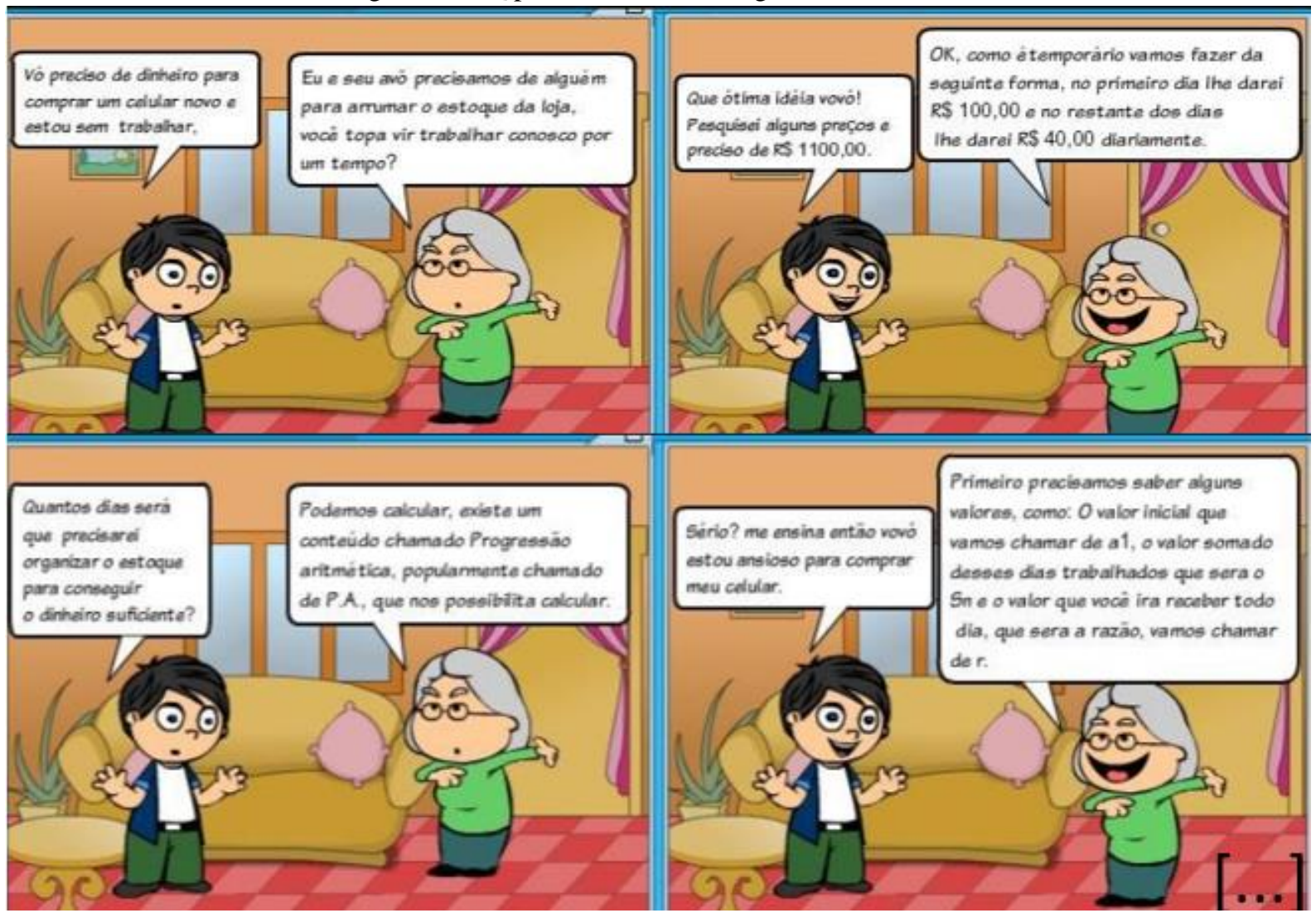

Fonte: Dados da pesquisa.

A Figura 2 tem o intuito de problematizar o conteúdo de progressão aritmética relacionando com uma situação bem próxima do cotidiano, favorecendo, assim, o entendimento e assimilação do tópico abordado.

Na sequência, a figura 3 apresenta o uso da HQ com o intuito de trabalhar o conceito de geometria espacial. 
Figura 3 - HQ exemplificando o cálculo de volume

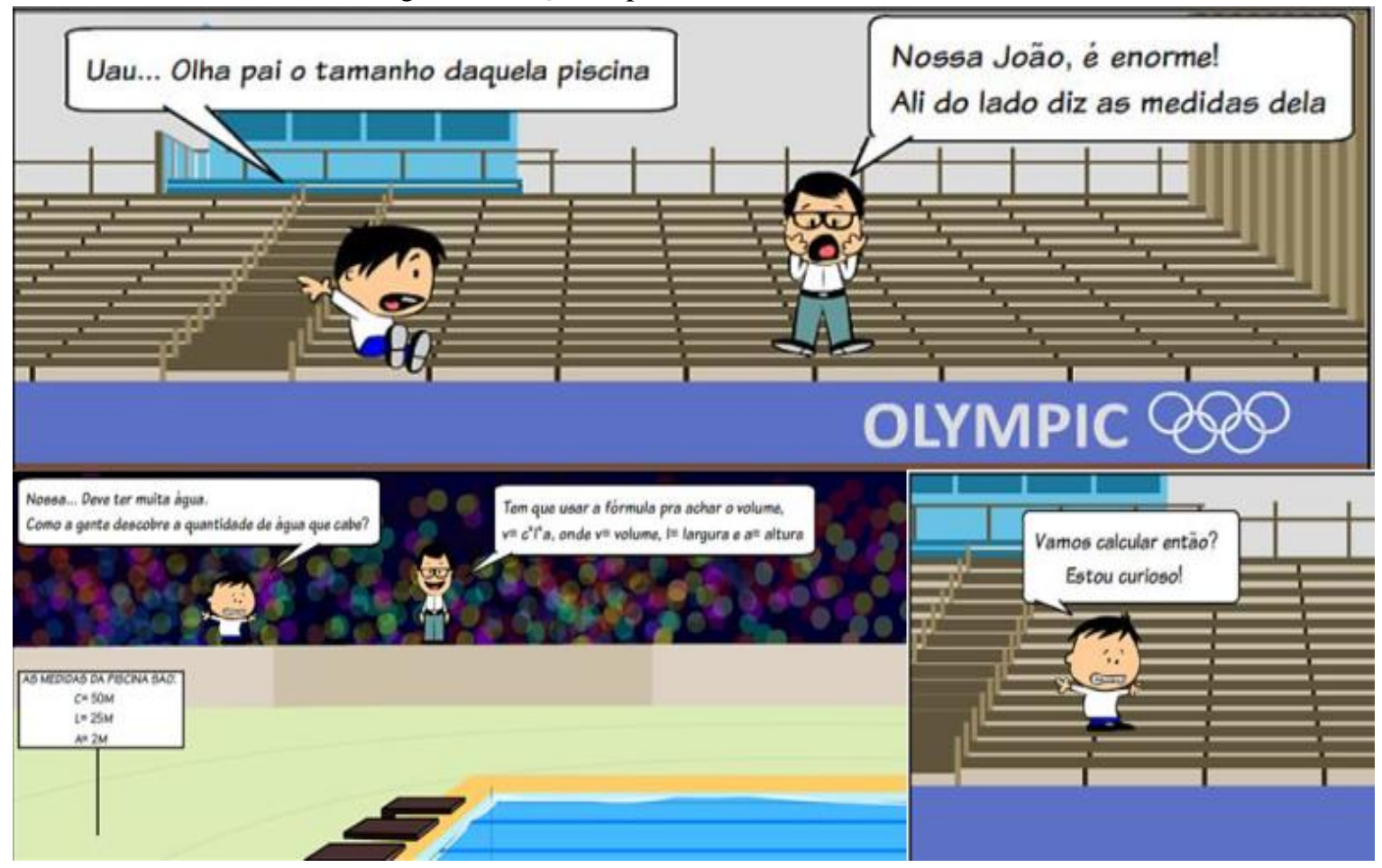

Fonte: Dados da pesquisa.

Observa-se, na HQ da Figura 3, a pretensão de explicar como pode ser calculada a quantidade de água que a piscina comporta, apresentando o modo que se determina o volume de um paralelepípedo, que é a figura geométrica que representa a piscina. Este exemplo de HQ pode ser utilizado para introduzir a temática a ser estudada, ou então utilizar para explicar o processo, apresentando as operações feitas para encontrar a solução, de maneira a atrair a atenção dos estudantes, sendo que os modos de aplicação podem variar de acordo com a criatividade do professor e do que ele pretende trabalhar.

Ao observar as Figuras 2 e 3, verifica-se que realmente é possível utilizar as HQ para problematizar, explicar, revisar ou até mesmo para introduzir situações matemáticas. Tal perspectiva possibilita aos futuros professores conhecer as diversas possibilidades de desenvolver atividades de matemática, de forma mais atrativa, que despertam o interesse dos estudantes e buscam desenvolver um conhecimento matemático mais significativo.

No momento de discussão no Facebook, através dos comentários, os licenciandos apontaram diferentes maneiras que pensaram em aplicar as histórias em quadrinhos dos colegas, assim como sugeriram novas problematizações e indicaram algumas melhorias.

A terceira atividade desenvolvida com os licenciandos foi a apresentação do software GeoGebra, que possui diversas funcionalidades para trabalhar diferentes conceitos de matemática, além de uma interface intuitiva que favorece a visualização e o movimento de 
figuras, planos, retas, dentre outros, que no quadro, às vezes não é possível mostrar. $\mathrm{O}$ GeoGebra tem sido muito utilizado nas aulas de matemática desde o Ensino Fundamental ao Ensino Superior, pelo fato de possibilitar que o estudante visualize o movimento enquanto o docente explica, favorecendo a aprendizagem e tornando a aula mais dinâmica.

Assim de início, a docente apresentou o site ${ }^{1}$ oficial que permite fazer o download do software e do aplicativo para celulares, e também encontrar suporte com vídeos tutoriais e materiais didáticos já construídos que podem ser usados no planejamento de aulas. Posteriormente, foram apresentadas e explicadas as principais funcionalidades do GeoGebra, sendo que cada acadêmico explorava o software em seu computador e executava os procedimentos conforme a docente lhes mostrava, possibilitando, assim, auxiliá-los em caso de dúvidas ou dificuldades.

Deste modo, os licenciandos se organizaram em grupos a fim de planejar uma atividade que envolvesse conteúdos do Ensino Médio, juntamente com um roteiro para aplicar aos seus colegas.

Nesta atividade, os alunos ainda estavam se apropriando das ferramentas do GeoGebra, suas atividades foram direcionadas ao estudo de funções. Alguns utilizaram as propriedades de controle deslizantes para mostrar a importância dos coeficientes em cada função, como podemos observar na figura 4.

Figura 4 - Controle deslizante com os coeficientes da função quadrática

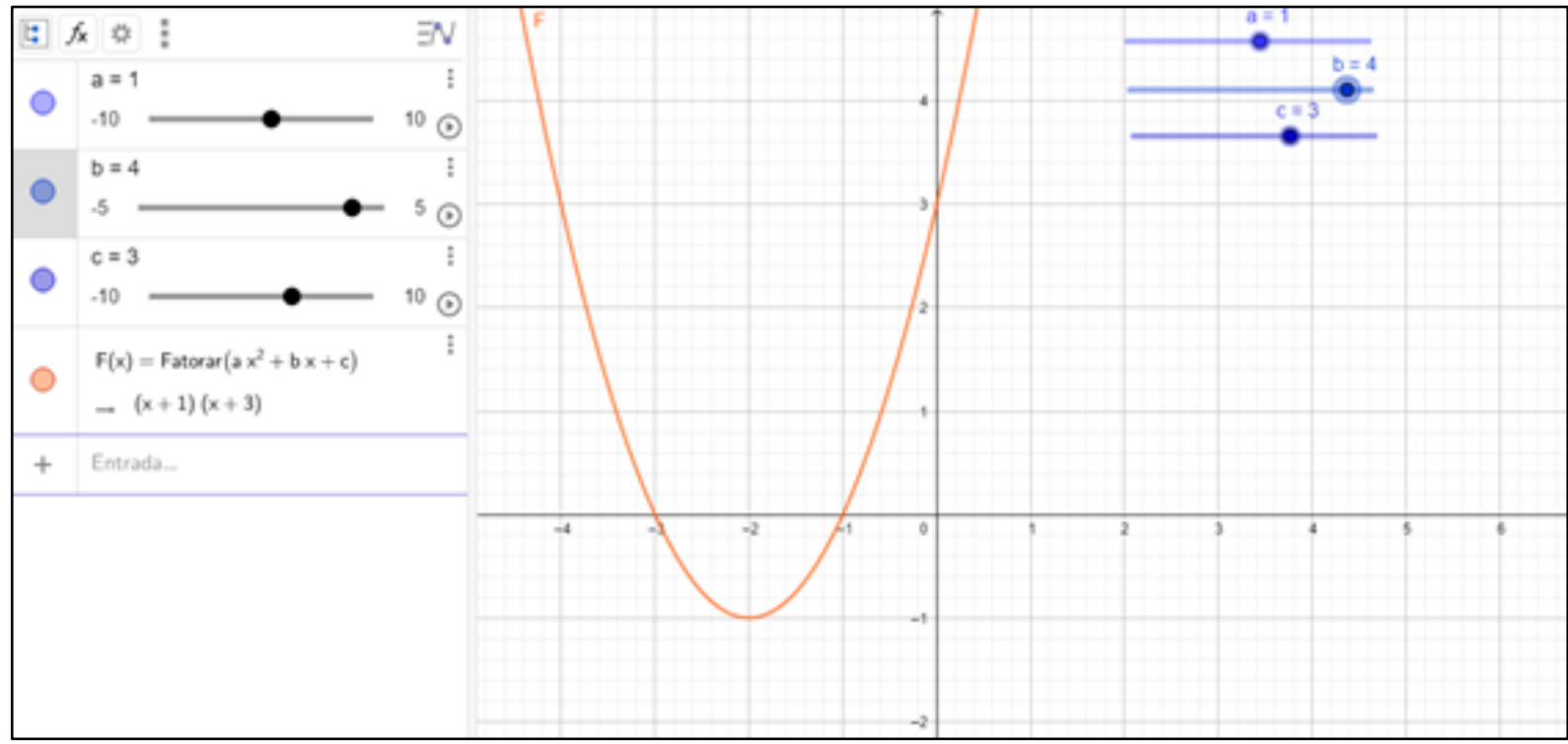

Fonte: Dados da pesquisa.

${ }^{1}$ www.geogebra.org 
Desse modo, ao alterar os valores do coeficiente a, b ou c, o gráfico da função se desloca automaticamente e permite que os estudantes compreendam qual o papel de cada coeficiente para o estudo da função quadrática.

O GeoGebra permite explorar o conceito de funções de diversos modos - determinando as raízes de uma função -, verificar a forma fatorada de uma função, identificar o vértice da função, entre outros conceitos. As atividades desenvolvidas no GeoGebra possibilitam um contato do acadêmico com o contexto virtual, mostrando a possibilidade de ensinar matemática de forma mais prazerosa, dinâmica, diferente do modo como estavam acostumados a estudar matemática na escola.

$\mathrm{Na}$ semana final do semestre, foi compartilhado com os licenciandos um questionário avaliativo. Quando questionados se consideravam que as atividades desenvolvidas na disciplina foram proveitosas e se poderiam repercutir em sua prática, todos responderam que sim, sendo que $80 \%$ concordaram plenamente e $20 \%$ parcialmente. Ao perguntar aos licenciandos se consideravam importante que o processo de formação estivesse relacionado às tecnologias, a maioria respondeu considerar que sim, pelo fato de:

Auxiliar no desenvolvimento do futuro docente (Licenciando A).

Porque o mundo em que vivemos, necessita de professores atualizados e sempre aprendendo [..] pois as tecnologias estão aí para nos ajudar (Licenciando B).

Atualmente vivemos no tempo da tecnologia e na escola deve ser inserida para que o processo de ensino e aprendizagem seja mais eficiente (Licenciando C).

Estes resultados corroboram com a importância da inserção das tecnologias em todo o processo de formação inicial de professores de matemática, de modo a ampliar a visão de mundo a respeito das tecnologias, e a partir disso modificar esta relação e, conscientemente, priorizar as melhores formas de integrá-las em sua prática docente.

Ainda, ao indagar os licenciandos quanto aos desafios que podem encontrar nas escolas, como organizaria sua aula e quais recursos utilizaria. Diante disso, apontaram como estratégias, primeiro verificar o contexto e realidade da escola, e se possível utilizar o celular, que dispõe de muitas funcionalidades e com o acesso à internet, possibilita utilizar diferentes aplicativos e recursos que podem agregar no desenvolvimento dos estudantes. Além disso, pensam em utilizar o GeoGebra, que permite o desenvolvimento de aulas de matemática mais dinâmicas; as histórias em quadrinhos, que permitem o trabalho de diversas formas e, por fim, os estudantes indicaram o uso dos jogos digitais. 
Importante destacar que o uso dos recursos tecnológicos deve ser pensado e planejado de acordo com cada realidade, e que devem ser utilizados de modo que os estudantes consigam visualizar situações que seriam difíceis de serem realizadas com o papel e caneta, beneficiandose dos recursos de som, cor, movimento, simulações que favorecem o entendimento e a representação de muitos conceitos matemáticos. Essas são novas formas de ensinar e aprender, proporcionadas pelas tecnologias e, por isso, é importante que professores estejam preparados para atender a esta tendência educacional.

\section{CONSIDERAÇÕES FINAIS}

Ao refletir sobre as tecnologias digitais no contexto escolar, é preciso considerar que as tecnologias estão cada vez mais presentes em uma parcela significativa das escolas, principalmente pelo uso dos estudantes, que demandam, dos professores e envolvidos no processo educacional, uma preparação para atuar neste cenário tecnológico em que a sociedade está vivendo.

No ensino de matemática, percebe-se que o uso das tecnologias digitais pode contribuir para mudanças no modo de ensinar e aprender os conceitos matemáticos. Acredita-se que, ao inserir propostas de ensino envolvendo as tecnologias digitais, desenvolvidas de maneira intencional, bem planejada, e com objetivos claros, é possível potencializar a compreensão dos conteúdos através das diversas funcionalidades que estimulem a criatividade, despertem o interesse dos estudantes, além de flexibilizar o ensino de matemática.

Considerando que cada estudante aprende de maneira diferente, é importante diversificar de forma criativa as estratégias, recursos e atividades nas aulas, de modo a contemplar as necessidades dos alunos e estimular a aprendizagem de todos através de meios variados. Diante disso, foram propostas três atividades distintas que possuem potencial para explorar diferentes habilidades e ritmos de aprendizagem de cada estudante. Incentivando assim, os licenciandos a refletirem e desenvolverem aulas que visam explorar essas habilidades.

Assim acredita-se que é fundamental que os cursos de formação inicial de professores de matemática assumam o compromisso de abordar as tecnologias digitais no decorrer de todo o curso, apresentando diferentes recursos tecnológicos que podem ser inseridos em suas aulas. Tal perspectiva proporciona aos licenciandos meios para desenvolver propostas que os estimulam a utilizarem como ferramentas potencializadoras do ensino de matemática.

Com isso, mobiliza-se futuros professores a refletir, conhecer, analisar criticamente e explorar a integração entre os recursos tecnológicos e os conceitos matemáticos, além de 
incentivá-los a serem autores no desenvolvimento de suas próprias atividades para o ensino de matemática. Dessa forma, visa-se a construção de atividades de ensino que incitem a criatividade, e não a mera reprodução de textos baseados na memorização de fórmulas, conceitos, aliados aos recursos tecnológicos, os quais demonstram ser uma boa alternativa para o desenvolvimento de saberes e atendem às necessidades dessa nova geração de estudantes da sociedade tecnológica.

\section{REFERÊNCIAS}

ALMEIDA, Murilena Pinheiro de.; REZENDE, Luiz Maurício Martins de.; LIMA, Siumara Aparecida de. A produção de vídeos digitais: uma situação de aprendizagem na formação de professores de ciências. REBECT. Ponta Grossa, v. 6, n. 2, p. 132 143, 2013. Disponível em: https://periodicos.utfpr.edu.br/rbect/article/view/1632. Acesso em: 26 abr. 2021.

BRASIL. Ministério da Educação. Resolução CNE/CP N 2, de 20 de dezembro de 2019. Diretrizes Curriculares Nacionais para a Formação Inicial de Professores para a Educação Básica e institui a Base Nacional Comum para a Formação Inicial de Professores da Educação Básica (BNC-Formação). 2019. Disponível em: http://portal.mec.gov.br/docman/dezembro2019-pdf/135951-rcp002-19/file. Acesso em: 28 abr. 2021.

BRASIL. Ministério da Educação. Resolução do CONSUP 13/2014. Diretrizes Institucionais Gerais e nas Diretrizes Curriculares Institucionais da Organização Didático-Pedagógica para os Cursos Superiores de Graduação do Instituto Federal Farroupilha. 2014. Disponível em: https://www.iffarroupilha.edu.br/regulamentos-elegisla\%C3\%A7\%C3\%B5es/resolu\%C3\%A7\%C3\%B5es/item/1343resolu\%C3\% A7\% C3\% A3o-consup-n\%C2\%BA-13-2014-diretrizes-institucionais-para-oscursos-superiores-de-gradua\%C3\%A7\%C3\%A30. Acesso em: 16 abr. 2021.

CORDEIRO, Nilton José Neves; CARDOZO, Daucília Araújo; SILVA, Márcio Nascimento da. Histórias em Quadrinhos: Algumas conexões com a matemática. Revista Educação Matemática em Foco. Campina Grande, v. 7, n. 3, p. 111-13, 2018. Disponível em: http://revista.uepb.edu.br/index.php/REVEDMAT/article/view/4540/3087. Acesso em: 15 maio 2021.

CHEN, Bayun; BRYER, Thomas. Investigar estratégias instrucionais para o uso de mídias sociais na aprendizagem formal e informal. The International Review of Research in Open and Distributed Learning- IRRODL, Canadá, v. 13, n. 1, 87-104, 2012. Disponível: https://doi.org/10.19173/irrodl.v13i1.1027. Acesso em: 08 maio 2021.

ELLENSOHN, Ricardo Machado; BARIN, Cláudia Smaniotto. Redes Sociais como ambiente de comunicação e aprendizado. Revista Tecnologias na Educação, Minas Gerais, v. 8, n. 14, 2016. Disponível em: http://tecedu.pro.br/wp-content/uploads/2016/07/Art34-vol14-jul2016Redes-sociais-como-ambientes-de-comunica\%C3\%A7\%C3\%A3o-e-aprendizado.pdf. Acesso em: 08 maio 2021.

FARIA, Eliane Turk. O professor e as novas tecnologias. In: ENRICONE, Délcia (Org.). Ser professor. 4. ed. Porto Alegre: EDIPUCRS, 2004. p. 57-72. 
FRIZZO, Bruna; BERNARDI, Giliane. Gibiquê - Sistema para Criação de Histórias em Quadrinhos. Centro Universitário Franciscano, Trabalho Final de Graduação II. Santa Maria, novembro/2001.

FÜRKOTTER, Monica.; MORELATTI; Maria Raquel Miotto. As tecnologias de informação e comunicação em cursos de licenciatura em Matemática. Série-Estudos, Campo Grande, s/v, n. 26, p. 51-64, 2008. Disponível em: https://serieucdb.emnuvens.com.br/serieestudos/article/view/204/275. Acesso em: 26 abr. 2021.

GLASSER, William. Willian Glasser. Disponível em: http://www.ppd.net.br/williamglasser/. Acesso em: 09 ago. 2021.

GONÇALVES, Elivelton Henrique; MARCO, Fabiana Fiorezi de. A formação de futuros professores de Matemática frente às tecnologias digitais. Renote, Porto Alegre, v. 18, n. 2, 2020. Disponível: https://doi.org/10.22456/1679-1916.110210. Acesso em: 23 abr. 2021.

KENSKI, Vani Moreira. Tecnologias e tempos docentes, Campinas: Papirus, 2013.

LOPES, Rosemara Perpetua. Formação para uso das Tecnologias Digitais de Informação e Comunicação nas licenciaturas das universidades estaduais paulistas. 2010. $226 \mathrm{f}$. Dissertação (Mestrado em Educação) - Universidade Estadual Paulista, Presidente Prudente, 2010.

MARTINS, Maria Cecília. Situando o uso da mídia em contextos educacionais. 2008. Disponível em: http://penta3.ufrgs.br/MEC-

CicloAvan/integracao midias/modulos/1 introdutorio/pdf/etapa2 1 situando usoMidias Bet h.pdf. Acesso em: 16 abr. 2021.

MISKULIN, Rosana Giaretta Sguerra; VIOL, Juliana. França. As práticas do professor que ensina matemática e suas interrelações com as tecnologias digitais. Revista e-Curriculum, São Paulo, v. 2, n. 12, maio/out. 2014. Disponível em:

https://www.redalyc.org/pdf/766/76632206012.pdf. Acesso em: 16 abr. 2021.

MORAN, José Manuel. A Educação que Desejamos: Novos desafios e como chegar lá. - $5^{\text {a }}$ ed. Campinas, SP: Papirus, 2012.

MORAES, Gustavo Pedroso; KOSLOWSKI, Sirlei; NONENMACHER, Sandra. Elisabet Bazana. Diferentes metodologias na formação inicial de professores de ciências da natureza. In: ENCONTRO MINEIRO SOBRE INVESTIGAÇÃO NA ESCOLA, 7, 2016. Anais... Uberlândia: EMIE, 2016. p. 1-6. Disponível em:

http://www.emie.facip.ufu.br/sites/emie.facip.ufu.br/files/Anexos/Bookpage/33.pdf. Acesso em: 19 maio 2021.

MOREIRA, Marco Antonio. Mapas conceituais e aprendizagem significativa. Revista Chilena de Educação Científica. v. 4, n. 2, p. 38-44, 2012. Disponível em: http://www.if.ufrgs.br/ moreira/mapasport.pdf. Acesso em: 15 maio 2021.

MOURA, Daniela Alves da Silveira; SANTOS, Alex da Silva dos; SILVA, Jhonatan Júnio da. Tecnologia a favor da Educação Matemática: Geogebra e suas aplicações. SynThesis Revista Digital FAPAM, Pará de Minas, v. 7, n. 1, p. 333-346, 2016. Disponível em: https://periodicos.fapam.edu.br/index.php/synthesis/article/view/146/144. Acesso em: 19 maio. 2021. 
MOUSINHO, Silvia Helena do Amaral. A utilização dos mapas conceituais como ferramenta didática nas licenciaturas de Física e Matemática do Cederj. Revista Educação Pública, v. 20, n. 4, 2020. Disponível em: https://educacaopublica.cecierj.edu.br/artigos/20/4/autilizacao-dos-mapas-conceituais-como-ferramenta-didatica-nas-licenciaturas-de-fisica-ematematica-do-cederj. Acesso em: 15 maio 2021.

NOVAK, Joseph. D.; CAÑAS, Alberto J. A. Teoria Subjacente aos Mapas Conceituais e como elaborá-los e usá-los. Práxis Educativa, v. 5, n. 1, p. 9-29, 2010. Disponível em: https://revistas2.uepg.br/index.php/praxiseducativa/article/view/1298. Acesso em: 15 maio 2021.

PASSERINO, Liliana Maria. Apontamentos para uma reflexão sobre a função social das tecnologias no processo educativo. Revista Texto Digital, Florianópolis, v. 6, n. 1, p. 58-77, 2010. Disponível em: https://doi.org/10.5007/1807-9288.2010v6n1p58. Acesso em: 28 abr. 2021.

PERIPOLLI, Patrícia Zanon; BARIN, Cláudia Smaniotto. Uso pedagógico de histórias em quadrinhos no ensino de matemática. In: CIET: EnPED, 2018, São Carlos. Anais eletrônicos... São Carlos: SEaD, 2018, p. 1-14. Disponível em: https://cietenped.ufscar.br/submissao/index.php/2018/article/view/239. Acesso em: 15 maio 2021.

SCHERER, Angelo Luís; FARIAS, Josefa Gomes de. Uso da Rede Social Facebook como Ferramenta de Ensino- aprendizagem em cursos de Ensino Superior. Revista Brasileira de Aprendizagem Aberta e a Distância, São Paulo, v. 17, n. 1, p. 1-20, 2018. Disponível em: http://dx.doi.org/10.17143/rbaad.v17i1.44. Acesso em: 10 maio 2021.

SOUSA, Renata Teófilo de; AZEVEDO, Italândia Ferreira de; ALVES, Francisco Régis Vieira. O GeoGebra 3D no Estudo de Projeções Ortogonais Amparado pela Teoria das Situações Didáticas. Jornal Internacional de Estudos de Educação Matemática, Londrina, v. 14, n. 1, p. 92-98, 2021. Disponível em: https://doi.org/10.17921/2176-

5634.2021v14n1p92-98. Acesso em: 19 maio 2021.

THIOLLENT, Michel. Metodologia da pesquisa-ação. 18 ed. São Paulo: Cortez, 2018.

TONON, Sandra de Fátima Tavares Rodrigues. As histórias em quadrinhos como recurso didático nas aulas de Matemática. Em Extensão, Uberlândia, v. 8, n. 1, jan. /jul, p. 72-81, 2009. Disponível em:

http://www.seer.ufu.br/index.php/revextensao/article/view/20433/10888. Acesso em: 22 jun. 2021.

TUCUNDUVA, Rodrigo. 7 redes sociais mais utilizadas no Brasil em 2021. 2021.

Disponível em: https://blog.lahar.com.br/midias-sociais/redes-sociais-mais-usadas-no-brasil/. Acesso em: 8 maio 2021.

\section{Agradecimentos}

O presente trabalho foi realizado com apoio da Coordenação de Aperfeiçoamento de Pessoal de Nível Superior (CAPES). 